\title{
Necrosis of choroidal melanoma: in ciliary artery involvement with temporal arteritis*
}

\section{J REIMER WOLTER}

From the Departments of Ophthalmology and Pathology of the University of Michigan Medical Center, Ann Arbor, Michigan, USA

SUMMARY A choroidal melanoma was clinically suspected in one eye of an 84-year-old farmer. At the time of the first examination the patient refused the studies necessary for a certain diagnosis as well as any treatment. Later, when the eye suddenly became blind and painful, it was enucleated. Pathological study revealed necrosis of all ocular contents, but the presence of a choroidal melanoma could still be verified histologically. The ciliary artery supplying the region of the melanoma was involved with giant cell arteritis. General examination of the patient gave support to a diagnosis of temporal arteritis, and steroid treatment resulted in general improvement.

So-called spontaneous necrosis of malignant melanomas of the choroid and ciliary body occurs in about $3.6 \%$ of cases and is commonly associated with secondary glaucoma, rubeosis iridis, uveitis, and atrophy of iris and ciliary body.' Melanoma necrosis is not a good sign prognostically and may be associated with extraocular tumour extension..$^{2-5}$ Fast growing uveal melanomas are predisposed to spontaneous necrosis because of an increased chance of the neoplasms to outgrow their blood supply. Both glaucoma and hypotony may contribute to necrosis of melanomas by causing regional collapse of arteries ${ }^{5}$ or stagnation in veins. ${ }^{6}$ Necrosis of choroidal melanomas should be expected to occur in temporal arteritis. However, to the best of our knowledge this is the first case with pathological evidence for such an association.

\section{Case report}

An 84-year-old farmer was referred by an optometrist for evaluation of suspected glaucoma and was first seen on 21 May 1984 . Vision at that time was $20 / 40$ in the right eye and $20 / 200$ in the left. Intraocular pressures measured by applanation were 27 $\mathrm{mmHg}$ in the right eye and $15 \mathrm{mmHg}$ in the left. Gonioscopy showed open angles in both eyes. Some

\footnotetext{
*Presented at the Georgina Dvorak Theobald Society Meeting, San Antonio, Texas, March 1985.

Correspondence to J R Wolter, MD, Departments of Ophthalmology and Pathology, University Medical Center, Ann Arbor, Mich. 48109, USA.
}

glaucomatous cupping with atrophy was found in the right eye. The left fundus, however, contained a golden brown mass under the elevated retina of the inferior temporal periphery. Diagnoses of open angle glaucoma in the right eye and suspected choroidal melanoma in the left eye were made. Medical treatment of the glaucoma was started. The patient was told about the diagnosis of suspected melanoma in the left eye and was advised to obtain a second opinion as a start for the proper management of the tumour. However, he agreed to have the glaucoma treated but refused any further diagnostic or therapeutic steps for the proper identification and treatment of the suspected melanoma.

The patient returned on 31 May 1984. The glaucoma in the right eye was very well controlled. Vision in the left eye had decreased to finger counting at $30 \mathrm{~cm}$. He came back again on 17 July 1984 and stated that he had suddenly become totally blind in the left eye and that the eye had become very painful. Examination showed it to be blind and beefy red, with swollen lids externally. A yellow exudate filled the anterior chamber. The deeper parts could not be seen. Intraocular pressures were $11 \mathrm{mmHg}$ in the right eye and $28 \mathrm{mmHg}$ in the left. The left eye was enucleated on 13 August 1984 and fixed in $10 \%$ formalin immediately.

\section{PATHOLOGICAL FINDINGS}

The eye was of normal size and did not show areas of direct extrascleral tumour extension. Transillumination did not allow for the demonstration of a clearly 


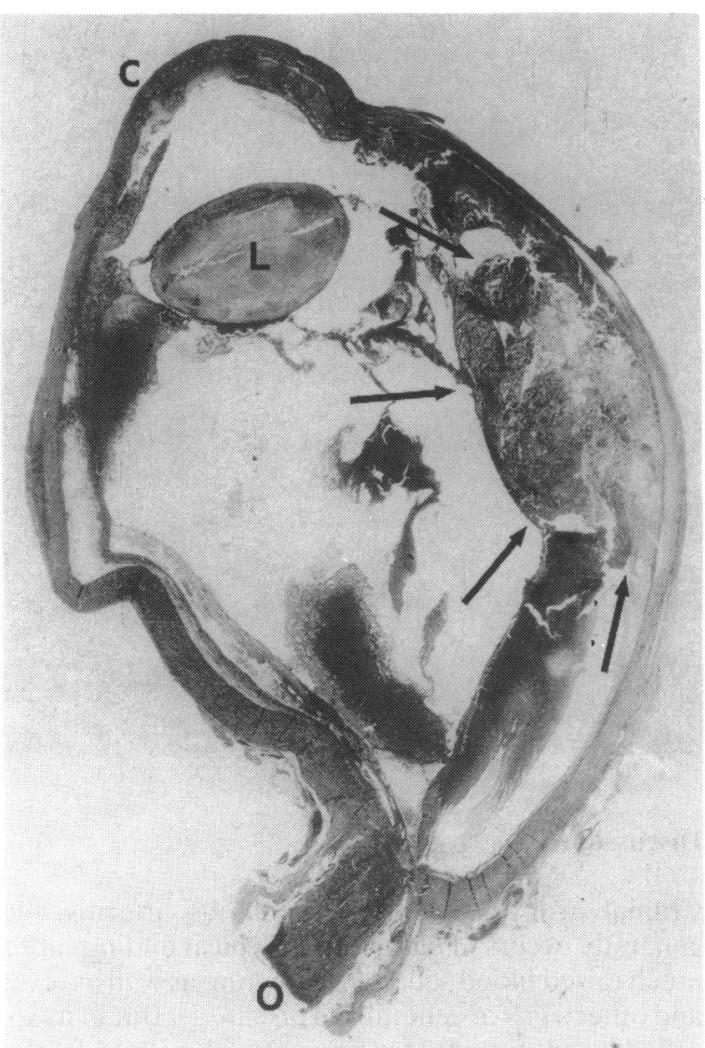

Fig. 1 Section of the whole eye in horizontal plane with cornea (C) and lens (L) above, necrotic melanoma (arrows) in temporal choroid, and optic nerve $(\mathrm{O})$ below. Paraffin section, $H$ and $E$ stain, $\times 4$.

outlined shadow in the area of the clinically suspected choroidal tumour. But the whole region of the temporal midperiphery and periphery was optically much more dense than the remainder of the eyediffusely, without sharp limits. When the eye was opened in a horizontal plane, the anterior chamber was found to be shallow and to contain old blood. The lens was relatively large. A choroidal tumour measuring $9 \times 7 \times 4 \mathrm{~mm}$ was found in the temporal midperiphery, in the region of the clinically suspected mass. This was of mushy consistency and black. The retina posterior to the tumour was detached, and the subretinal space contained a mixture of old blood and exudate. Dark blood and debris also filled the vitreous space.

Microscopic sections cut in the horizontal plane (Fig. 1) showed loss of most of the corneal epithelium. The corneal stroma was swollen, and Descemet's membrane was preserved. The corneal endothelium showed diffuse loss of cells but was preserved as a continuous layer. A mixture of blood

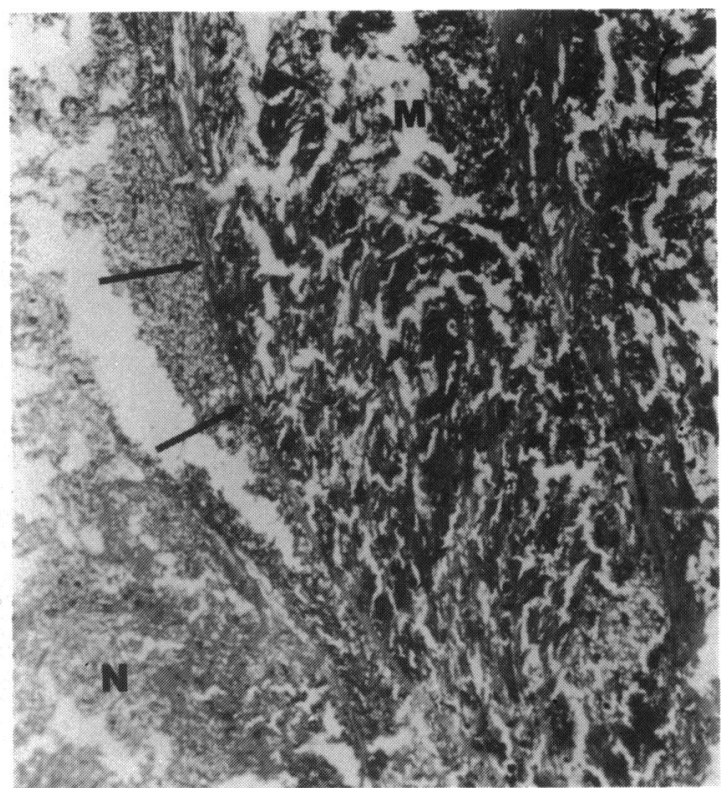

Fig. 2 Higher power shows necrotic preservation of spindle-shaped cells in area of choroidal melanoma (M). Bruch's membrane preserved (arrows). Amorphous necrotic material $(\mathrm{N})$ in region of adjacent retina. Paraffin section, $H$ and $E$ stain, $\times 315$.

and exudate containing many pigment-filled macrophages was found in the shallow anterior chamber. The chamber angle was narrow on the nasal side and it was closed by anterior peripheral synechiae temporally. The iris was partly necrotic, but it was preserved in parts of its substance and in its outlines. The ciliary body also showed partial necrosis on the nasal side and total necrosis on its temporal aspects. The lens was swollen and cataractous. It contained small areas of calcification.

The choroid in the midperiphery on the temporal side contained a totally necrotic pigmented tumour (Fig. 1). Higher magnification clearly showed necrotic preservation of bundles of spindle cells of shape and arrangement typical of uveal melanoma (Fig. 2) in the area of the clinically and grossly observed tumour of the choroid. Bruch's membrane was visible on the inner surface of the main mass of the choroidal tumour (Fig. 2). The remainder of the choroid and the retina were also mostly necrotic, but they too were preserved in their outlines and main components. The vitreous space contained blood and exudate in irregular distribution (Fig. 1). Retroretinal haemorrhage was recognised on the temporal side between uveal tumour and optic nerve head. On the nasal side the retina was thickened owing to partial disintegration (Fig. 1). The optic nerve was 
Fig. 3 Preserved structures of optic nerve head: optic nerve $(\mathrm{O})$, lamina cribrosa $(\mathrm{L})$, central artery $(\mathrm{A})$, vein $(\mathrm{V})$, retina $(\mathrm{R})$, preretinal exudate $(\mathrm{E})$, choroid $(\mathrm{C})$, perivascular infiltration $(\mathrm{P})$, and sclera (S). Arrow points to vacuolic degeneration in nerve substance of disc. Paraffin section, $H$ and $E$ stain, $\times 57$.

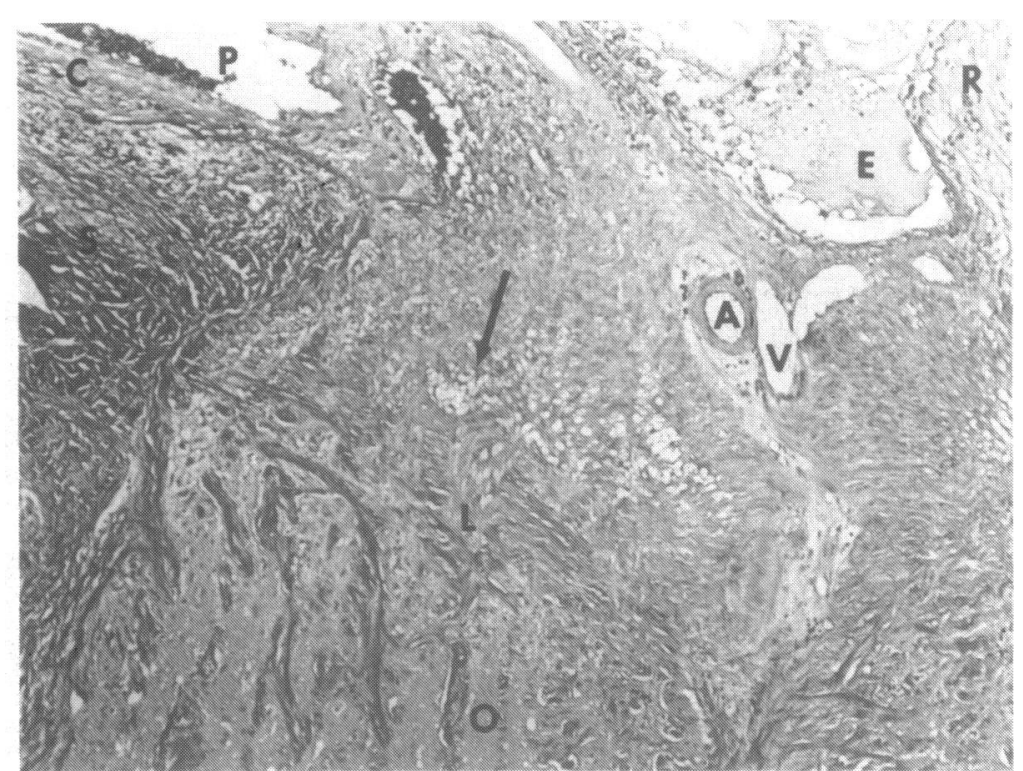

preserved in its structures but lacked living cells in its anterior portion. Destruction of nerve substance with formation of lipid vacuoles was seen in the optic nerve head (Fig. 3). The central retinal vessels were open, but they did not contain blood (Fig. 3). The sclera and optic nerve sheaths were normal.

Granulomatous arteritis with epithelioid and giant cells as well as extensive perivascular accumulation of small mononuclear cells was found to involve the long posterior ciliary artery at its entry site on the outside of the sclera on the temporal side (Figs. 4 and 5). Giant cells of the Langhans type were located on the outside of the arterial muscle layer next to degenerating inner elastic lamina (Fig. 5) and there also were local degeneration of arterial muscle cells and some intimal fibrosis (Fig. 5). Serial sections showed that the same artery on its course into the sclera and choroid towards the necrotic choroidal tumour did not exhibit signs of arteritis. While the artery contained blood in its lumen in the zone of inflammatory involvement on the outside of the sclera (Fig. 5), it was filled with exudate only-and not with blood on its further course in sclera and choroid into the inner eye.

A pathological diagnosis of temporal arteritis in an eye with a necrotic choroidal melanoma was made. Clinical examination showed a sedimentation rate of $27 \mathrm{~mm} / \mathrm{h}$ associated with other signs and symptoms of possible temporal arteritis. Treatment with prednisone $10 \mathrm{mg}$ four times daily was started. Vision in the right eye remained good. The patient is still alive and without evidence of metastatic or recurrent melanoma.

\section{Discussion}

Cranial arteritis is a granulomatous arteritis and generally occurs in old people. Typical findings are a much raised blood sedimentation rate as well as fever and other signs of generalised disease..$^{711}$ But in its socalled occult form it may present with sudden loss of vision." The visual loss is usually irreversible, but at

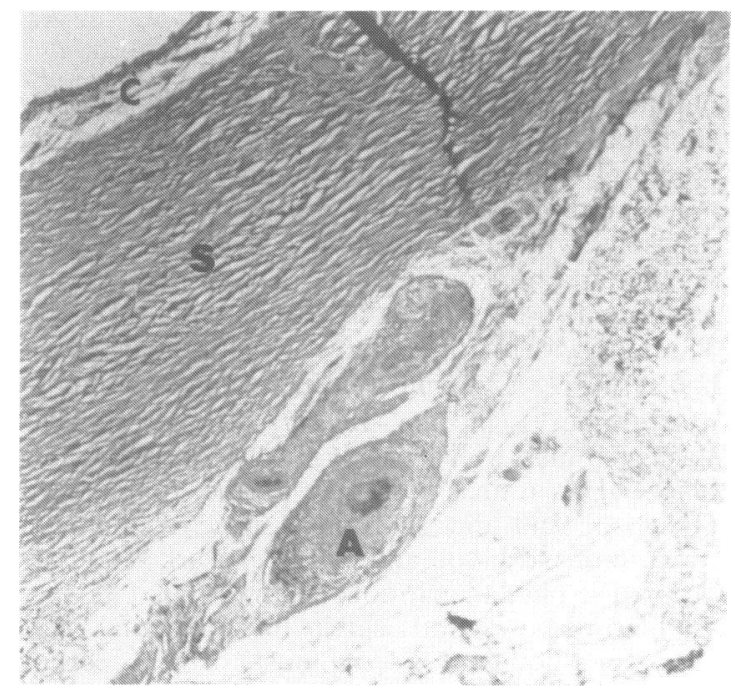

Fig. 4 Posterior temporal aspect of sclera (S) and choroid (C) with long posterior ciliary artery (A) exhibiting granulomatous arteritis directly before entry into sclera $(\mathrm{S})$. Paraffin section, $H$ and $E$ stain, $\times 54$. 


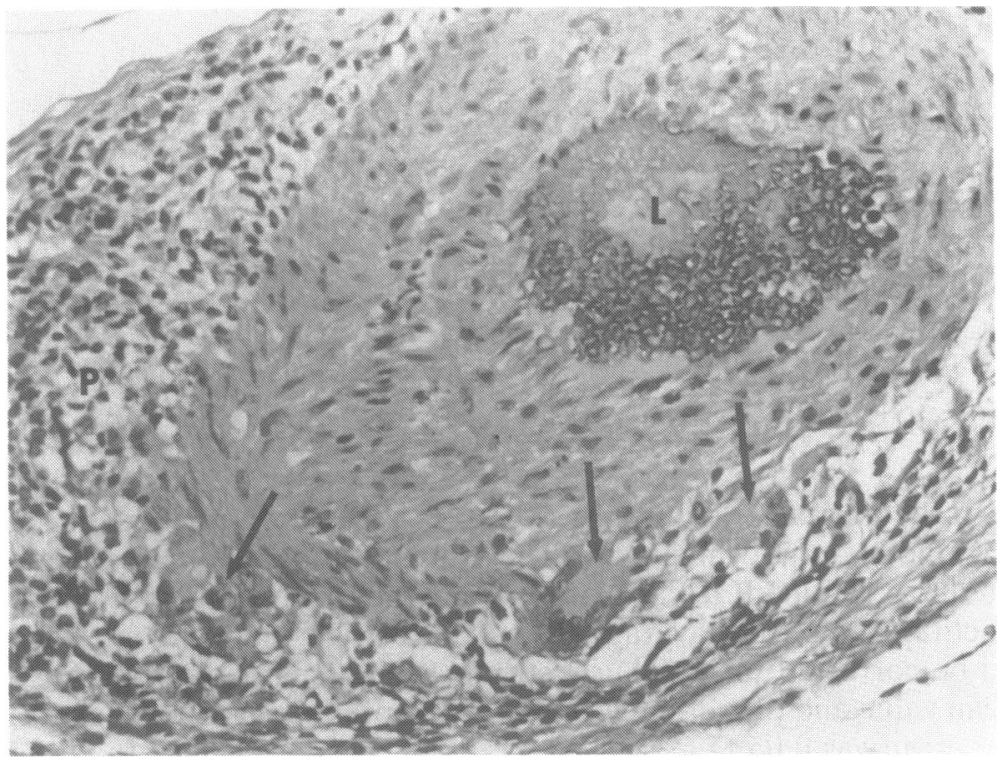

Fig. 5 Long posterior ciliary artery on outside of sclera with massive perivascular infiltration $(\mathrm{P})$ and giant cells (arrows) next to degenerating inner elastic lamina in its wall. Arterial lumen (L) preserved and filled with blood. Paraffin section, $H$ and $E$ stain, $\times 330$.

first it usually involves only one eye. Histological examination of eyes blinded by temporal arteritis usually reveals granulomatous inflammation in extrascleral portions of the ciliary arteries or extradural parts of the central retinal artery. Special stains show the granulomatous reaction to be centred on degenerating elastic fibres and smooth muscle. ${ }^{11}$ 12 Rubeosis leading to secondary glaucoma further complicates the clinical picture of temporal arteritis. ${ }^{13-15}$ But there was no evidence of any relationship between the glaucoma in the right eye and the temporal arteritis in the present case.

Temporal arteritis is a disease of many faces, and with the advances in diagnosis and therapy it is rarely seen now in its fully developed form. It should be suspected in cases of sudden visual loss in old patients, and a temporal artery biopsy is considered the clinically most reliable method for its recognition. The histological observation of typical giant cell arteritis in the long posterior ciliary artery supplying the uveal region of the melanoma in the present case counts at least as the equivalent of a positive temporal artery biopsy diagnostically. The giant cell arteritis in this ciliary artery, furthermore, may explain the necrosis of the melanoma. Massive necrosis of parts of the inner eye is known to produce necrotoxins and to have a tendency to involve all intraocular structures. In this process an endophthalmitis-like syndrome with much pain is apt to develop.

This work was supported by the Research to Prevent Blindness Inc. New York. NY.

\section{References}

1 Bujara K. Necrotic malignant melanomas of the choroid and ciliary body. Graefes Arch Clin Exp Ophthalmol 1982: 219: 40-3.

2 Callender GR, Wilder HC, Ash JE. Five hundred melanomas of the choroid and ciliary body followed 5 years or longer. $A m J$ Ophthalmol 1942: 25: 962-7.

3 Paul EV, Parnell LC. Fraker M. Prognosis of malignant melanoma of the choroid and ciliary body. Int Ophthalmol Clin 1962: 2: 387-402.

4 Reese AB. Archilla EA. Jones IS, Cooper WC. Necrosis of malignant melanoma of the choroid. Am J Ophthalmol 1970; 69: 91-104.

5 Bujara K. Domarus Dv. Guthoff R. Nekrotisches malignes Melanom der Aderhaut mit ungewoehnlichem klinischen Verlauf. Ophthalmologica 1980; 180: 222-7.

6 Wolter JR. Petrauskas RR. Massive necrosis of choroidal melanoma following paracentesis. Eye Ear Nose and Throat Monthly 1968: 47: 31-4.

7 Saeve-Soederbergh J. Malmvall BE, Anderson R, Bengtson BA. Giant cell arteritis as a cause of death. JAMA 1986; 255: 493-6.

8 Wagener HP. Hollenhorst RW. The ocular lesions of temporal arteritis. Am J Ophthalmol 1958: 45: 617-30.

9 Simmons RJ, Cogan DG. Occult temporal arteritis. Arch Ophthalmol 1962; 68: 38-48

10 Wang FM. Henkind P. Visual system involvement in giant cell (temporal) arteritis. Surv Ophthalmol 1979; 23: 264-71.

11 Reinecke RD. Kuwabara T. Temporal arteritis I: smooth muscle involvement. Arch Ophthalmol 1969; 82: 446-53.

12 McDonnell PJ, Moore GW, Miller NR, Hutchins GM, Green WR. Temporal arteritis: a clinicopathologic study. Ophthalmology 1986: 93: 518-30.

13 Copetto JR, Monteiro MLR, Sciarra R. Giant-cell arteritis with bilateral uveitic glaucoma. Ann Ophthalmol 1985: 17: 299-302.

14 Wolter JR. Phillips RL. Secondary glaucoma in temporal arteritis. Am J Ophthalmol 1965: 59: 625-34.

15 Boberg-Ans J, Nielsen NV. Neovascular glaucoma as the primary ocular complication in temporal arteritis. Glaucoma 1986: 8: $138-40$

Accepted for publication 25 February 1988. 